\title{
The Effect of Immunotherapy on Humoral and Cellular Responses in Ragweed Hayfever
}

\author{
Richard Evans, Hobert Pence, Hyman Kaplan, and \\ Ross E. RockLIN \\ From the Allergy-Immunology Service, Walter Reed Army Medical Center, \\ Washington, D. C. 20012
}

\begin{abstract}
A B S T R A C T The effect of specific immunotherapy on several in vitro responses to ragweed antigen $E$ has been evaluated in 17 atopic patients with ragweed hayfever. The methods employed were leukocyte histamine release, measurement of specific $\mathrm{IgE}$ anti-ragweed antibody and specific IgG anti-ragweed antibody, lymphocyte proliferation, and the production of two lymphocyte mediators (migration inhibitory factor and mitogenic factor). The duration of treatment and symptom improvement were also recorded for comparison.

Immunotherapy was associated with a decrease in leukocyte sensitivity for histamine release to ragweed antigen $E$ in a majority of the patients. In addition, there was a significant decrease in $\operatorname{IgE}$ anti-ragweed antibody and a significant increase in IgG anti-ragweed antibody. Immunotherapy also resulted in a significant decrease in lymphocyte responsiveness to ragweed antigen $\mathrm{E}$ as measured by proliferation and the production of mediators. Symptomatic improvement was best correlated with the presence of IgG anti-ragweed antibody responses. The production of this antibody was also associated with a decrease in lymphocyte responsiveness. The results of this study indicate that specific immunotherapy in ragweed-sensitive patients induces alterations in immunologic reactivity to ragweed antigen in vitro. This response is antigen specific, includes elements of both humoral and cellular immunity, and may account
\end{abstract}

This work was presented in part at the 30th Annual Meeting of the American Academy of Allergy, 19-23 January 1974.

Dr. Pence's present address is the Allergy-Immunology Service, Brooke Army Medical Center, Fort Sam Houston, Tex. 78234; Dr. Kaplan's present address is the AllergyImmunology Service, Moncrief Army Medical Center, Fort Jackson, S. C. 29209 ; and Dr. Rocklin's present address is the Department of Medicine, Robert B. Brigham Hospital, Boston, Mass. 02120.

Received for publication 29 September 1975 and in revised form 5 January 1976. for the clinical improvement that is often observed in patients who undergo this form of therapy.

\section{INTRODUCTION}

Ragweed hayfever has classically been attributed to mechanisms of immediate hypersensitivity involving reaginic $(\mathrm{IgE})$ antibodies (1). However, recent evidence suggests that cellular immune responses to ragweed antigen may also be detected (2-8). In our previous study (2) we measured a broad range of immunologic responses including antigen-induced leukocyte histamine release, the radioallergosorbent test (RAST) ${ }^{1}$ for specific IgE antiragweed antibody ( $I g E A R$ ), lymphocyte proliferation, and the production of two lymphocyte mediators, migration inhibitory factor (MIF) and mitogenic factor (MF). We found that the majority of patients who were sensitive to ragweed antigen E (RAgE) in terms of histamine release and had higher titers of specific IgEAR also demonstrated enhanced lymphocye proliferation and mediator production.

The purpose of the present study was to evaluate the immunologic changes accompanying specific immunotherapy to ragweed antigen in patients with ragweed hayfever. The same immunologic parameters were measured with one addition, the specific IgG antiragweed antibody (IgGAR) (blocking) titers before and after therapy. The results of this study show the immunologic changes resulting from immunotherapy to be com-

${ }^{1}$ Abbreviations used in this paper: IgEAR, IgE antiragweed antibody; IgGAR, IgG antiragweed antibody; MF, mitogenic factor; MIF, migration inhibitory factor; PBS, phosphate-buffered saline; PNU, protein nitrogen unit; RAgE, ragweed antigen E; RAST, radioallergosorbent test; $r^{*}$, Spearman rank correlation coefficient; S/C, stimulated to control ratio; SK-SD, streptokinase-streptodornase; $T$ cell, thymus-derived lymphocyte; WRE, whole ragweed pollen extract. 
plex, involving a decrease in $\operatorname{IgEAR}$ synthesis, a decrease in both leukocyte and lymphocyte reactivity, and increased production of anti-ragweed IgG blocking antibody. These changes were associated with marked clinical improvement in our patient group.

\section{METHODS}

Patient selection and treatment. 17 of 28 atopic patients from our original study (2) with symptoms of allergic rhinitis in the ragweed pollenation season were successfully restudied after 6-18 mo of immunotherapy. Some attrition resulted from the transfer of patients to other parts of the country or world and only the data from 17 who remained in the Washington area during treatment are included in this study. These patients all had a significantly positive skin test reaction to the intradermal injection of $0.02 \mathrm{ml}$ of a 100 -protein nitrogen unit $(\mathrm{PNU}) / \mathrm{ml}$ aqueous ragweed extract. None of the patients had previously received specific immunotherapy. Immunotherapy with aqueous whole ragweed extract (WRE) was administered in total doses of $1,400-190,000$ PNU with a median of 10,500 PNU. This was given over a period of 6-18 mo with a median of 9 mo. The patients were asked to record symptom improvement during the ragweed season immediately following immunotherapy. None of the in vitro tests were done during the ragweed season or the 8-wk period immediately after.

Specific IgEAR titers. The RAST was used to measure serum specific IgEAR before and after treatment (9). The antigen-cellulose conjugate was prepared with $20 \%$ WRE and cyanogen bromide-activated cellulose particles. The immunosorbent purified anti-IgE $(\mathrm{Fc})$, kindly supplied by Doctors C. E. Arbesman and John Wypych, was labeled by the chloramine $\mathrm{T}$ method (10). All samples were tested at the same time and serum from a known ragweed-sensitive patient was included in the experiment as a reference standard.

Antigen-induced leukocyte histamine release. The method used was that of Lichtenstein and Osler as modified by May et al. for small amounts of blood (11). Venous blood samples were collected before and after immunotherapy. Leukocytes were isolated, washed, and suspended in the appropriate buffer. RAgE (kindly supplied by Dr. C. Kirkpatrick, National Institute of Allergy and Infectious Diseases, $\mathrm{Na}$ tional Institutes of Health) was added to the cell suspension in amounts of $10^{-6}-10^{-1} \mu \mathrm{g} / \mathrm{ml}$ by using threefold dilutions. The released histamine was measured by a fluorometric technique. The concentration of antigen required to elicit release of $50 \%$ of the total cellular histamine was used as an indication of the cell sensitivity (6).

Specific IgGAR level. A double antibody technique recently described by Sobotka et al. was used to measure IgGAR (12). RAgE was radiolabeled by the chloramine $\mathrm{T}$ method. $2 \mathrm{mCi}^{125} \mathrm{I}$ in $\mathrm{NaOH}(0.01 \mathrm{ml})$ was used to label 30 $\mu \mathrm{g}$ of $\mathrm{RAgE}$ in the presence of $0.05 \mathrm{mg}$ of chloramine $\mathrm{T}$ diluted in phosphate-buffered saline (PBS), $\mathrm{pH}$ 7.4. The total reaction volume is $0.110 \mathrm{ml}$. This is mixed exactly $1 \mathrm{~min}$ and the reaction stopped by the addition of $0.1 \mathrm{ml}$ of sodium metabisulfite $(0.5 \mathrm{mg} / \mathrm{ml})$ in $\mathrm{PBS}, \mathrm{pH}$ 7.4. The labeled $\mathrm{RAgE}$ is suspended in an additional $0.2 \mathrm{ml}$ of $\mathrm{PBS}$ (containing $5 \% \mathrm{BSA}$ and $8 \mathrm{mg} / \mathrm{ml}$ potassium iodide). Free ${ }^{225} \mathrm{I}$ is removed by application to a G-25 Sephadex column (Pharmacia Fine Chemicals, Inc., Piscataway, N. J.). The specific activity was $5.6 \times 10^{8} \mathrm{cpm} / \mu \mathrm{g}$ of ${ }^{125} \mathrm{I}$-labeled RAgE. Serial dilutions of the patient's sera were incubated for $4 \mathrm{~h}$ at room temperature with ${ }^{125} \mathrm{I}$-labeled RAgE. Hyperimmune goat anti-human IgG was then added in excess. The protein was precipitated overnight, centrifuged, and washed, and the $\mathrm{cpm}$ measured with a gamma counter. A standard sera of high titer IgGAR was also included and the result recorded as a percent of the total radioactivity bound by a $1 / 100$ dilution of the standard sera.

Lymphocyte proliferation ( $\left[{ }^{3} \mathrm{H}\right]$ thymidine incorporation). Samples of heparinized blood were collected before and after immunotherapy in each patient. Lymphocytes, isolated by centrifugation on a Ficoll-Hypaque gradient, were washed and cultured in medium TC-199 (Microbiological Associates, Bethesda, Md.) containing $15 \%$ plasma (13). Autologous plasma was used in the pretreatment experiments, and both autologous and homologous plasma were used in paired posttreatment experiments. The cells were cultured alone, in the presence of $\operatorname{RAgE~}(50,25$, and $12.5 \mu \mathrm{g} / \mathrm{ml}$ ) and in the presence of streptokinase-streptodornase (SK-SD) $(50$ $\mathrm{U} / \mathrm{ml}$ ) for 6 days. $6 \mathrm{~h}$ before terminating the cultures $\left[{ }^{3} \mathrm{H}\right]-$ thymidine (sp act $6.7 \mathrm{mCi} / \mathrm{mmol}$. New England Nuclear, Boston, Mass.), $1 \mu \mathrm{Ci} /$ tube, was added. The precipitable protein was isolated and the cpm determined by scintillation counting (14). Stimulation ratios were calculated by dividing the mean cpm (duplicate cultures) of antigen stimulated cultures by the cpm of unstimulated (control) cultures.

Preparation and assay of lymphocyte $M F$. Isolated lymphocytes ( 15 million per tube in $1.5 \mathrm{ml}$ ) were cultured without antigen (control) and in the presence of $75 \mu \mathrm{g} / \mathrm{ml}$ of $\mathrm{RAgE}$ for $48 \mathrm{~h}$ (15). At the end of the incubation period, the cell-free supernates were collected and the control supernate reconstituted with antigen $(75 \mu \mathrm{g} / \mathrm{ml})$. Control and "active" supernates were diluted $1 / 3$ and $1 / 6$ and assayed for mitogenic activity on autologous lymphocytes. The mitogenic activity of supernates was calculated by subtracting the cpm of control supernates from the stimulated supernate.

Preparation and assay for MIF. Lymphocyte production of MIF was determined by the method of Rocklin et al. (15). Lymphocytes collected before and after treatment were cultured in serum-free medium without antigen and in the presence of RAgE (50 $\mu \mathrm{g}$ protein $/ \mathrm{ml})$ and SK-SD $(50 \mathrm{U} / \mathrm{ml})$. Cell-free supernates were collected for 3 days, pooled, concentrated, and assayed for MIF activity with guinea pig macrophages in capillary tubes as the indicator cells.

Sympton evaluation. Each patient was asked to maintain a diary of symptoms experienced during the subsequent ragweed season and then to summarize his treatment response. A scale of 1-5 was established. This represented a range from more severe symptoms to no symptoms as compared to the previous ragweed season.

Analysis of data. The data was analyzed for statistical significance by Student's $t$ test for paired means or for rank correlation by means of the Spearman rank correlation coefficient $\left(r^{*}\right)(16)$

\section{RESULTS}

Specific anti-ragweed IgE antibody. The effects of immunotherapy on serum levels of specific IgEAR (RAST titer) are summarized in Fig. 1.6 of the 17 patients did not have pretreatment titers above the $5 \%$ found in normal controls. The same patients also did not have a rise in the RAST titers after immunotherapy. In the 11 patients with elevated pretreatment RAST titers, immunotherapy was followed by a decrease in the titer in 8 patients, an increase in 1 patient, and no change in 2 patients. The mean pretreatment IgEAR 


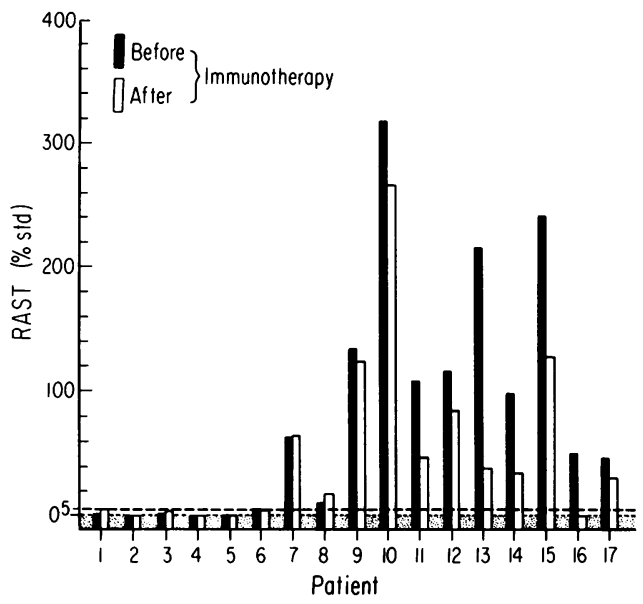

Figure 1 Specific IgEAR (RAST \% std) levels in patients' sera before and after immunotherapy.

titer was $83 \%$, the mean posttreatment, $50 \%$. This change is significant for paired values at $P<0.025$ ( $t$ test).

Specific IgGAR. IgGAR was not detectable at a $1 / 100$ dilution of the pretreatment sera (Fig. 2). After treatment IgGAR was found in every patients' sera at this concentration. The percent of total counts bound ranged from 8 to 93 . A rise in IgGAR occurred in all the patients and was not dependent upon initial IgEAR or leukocyte sensitivity to $\mathrm{RAgE}$ for histamine release. There was a highly significant correlation $\left(r^{*}=0.76\right.$; $P=<0.001)$ between the IgGAR titer and symptom improvement. The IgGAR titer was higher in patients receiving larger total accumulative doses of ragweed extract treatment $\left(r^{\circ}=0.49 ; P=<0.05\right)$. Furthermore, there was an inverse relationship between the increase in IgGAR titer and the decrease in IgEAR titer $\left(r^{*}=\right.$ $0.57 ; P<0.05)$.

Leukocyte histamine release. In Fig. 3 , the concentration of $\mathrm{RAgE}$ required to elicit $50 \%$ cellular hista-

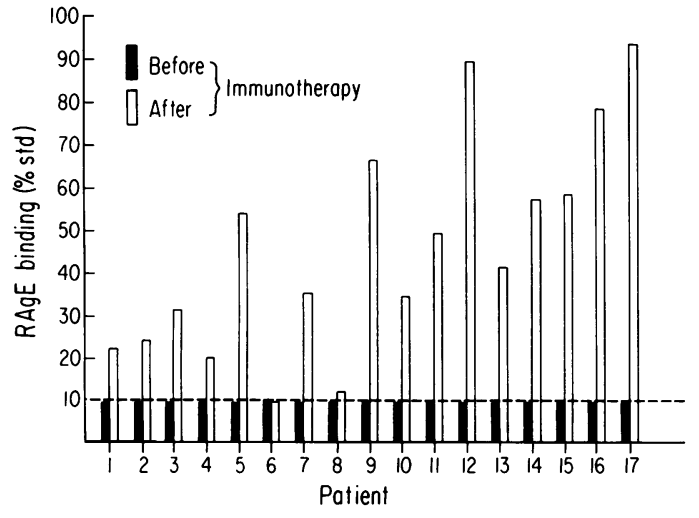

FIgure 2 Specific IgGAR bound to radiolabeled RAgE before and after immunotherapy.

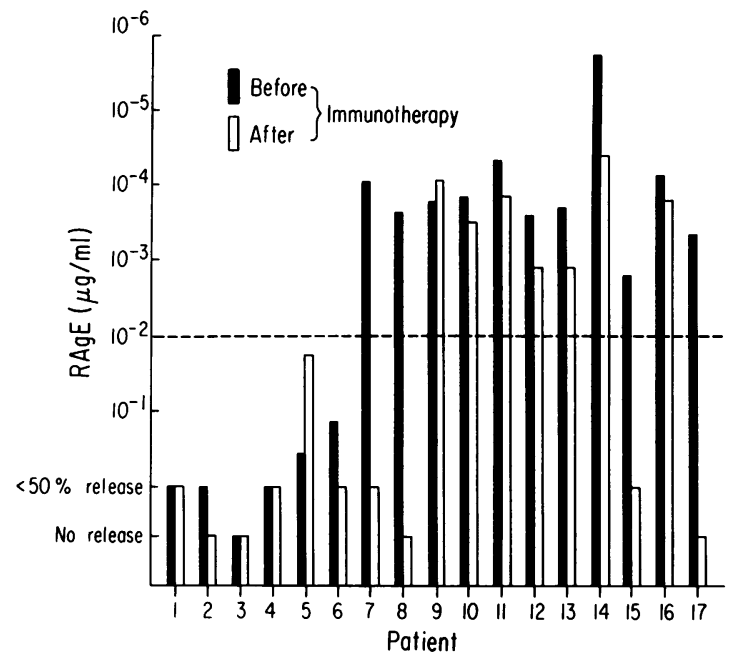

Figure 3 Leukocyte sensitivity to RAgE before and after immunotherapy.

mine release is recorded as the leukocyte sensitivity of that patient. Based on repeated experiments, 10-fold changes in antigen concentrations were considered significant. When the in vitro cellular histamine release was less than $50 \%$ or when the antigen concentration required was greater than $10^{-2} \mu \mathrm{g}$ protein $/ \mathrm{ml}$, the patients' leukocytes were considered to be relatively insensitive. This relative insensitivity to $\mathrm{RAgE}$ for leukocyte histamine release was found in the same six patients who had low serum RAST titers. This insensitivity remained after immunotherapy. A significant decrease in sensitivity to $\mathrm{RAgE}$ following immunotherapy was found in 5 of the remaining 11 sensitive patients.

Lymphocyte transformation. The amount of $\left[{ }^{3} \mathrm{H}\right]-$ thymidine incorporated into cellular DNA in response to three different $\mathrm{RAgE}$ concentrations and SK-SD was measured and the ratio of stimulated (S) to unstimulated (C) cultures calculated. The highest $\mathrm{S} / \mathrm{C}$ ratios calculated are recorded in Fig. 4. The stimulation indices are for autologous plasma before immunotherapy and autologous plasma and homologous plasma after immunotherapy. This index was greater than the mean control response of 3 in all but one of the pretreatment ragweed-sensitive patients. After immunotherapy, 13 of 16 patients had a decrease in this ratio in autologous plasma, and 11 of 16 manifest a decrease in homologous plasma. The mean pretreatment $\mathrm{S} / \mathrm{C}$ ratio was 20.7 . The mean posttreatment $\mathrm{S} / \mathrm{C}$ ratios were 8.0 in autologous plasma and 9.8 in homologous plasma. In both instances, the decrease in $\mathrm{S} / \mathrm{C}$ index is significant for paired means, $P<0.005$ ( $t$ test). The patients with the higher pretreatment lymphocyte stimulation indices were not consistently the same patients who were more sensitive in the leukocyte histamine release and RAST tests. The 


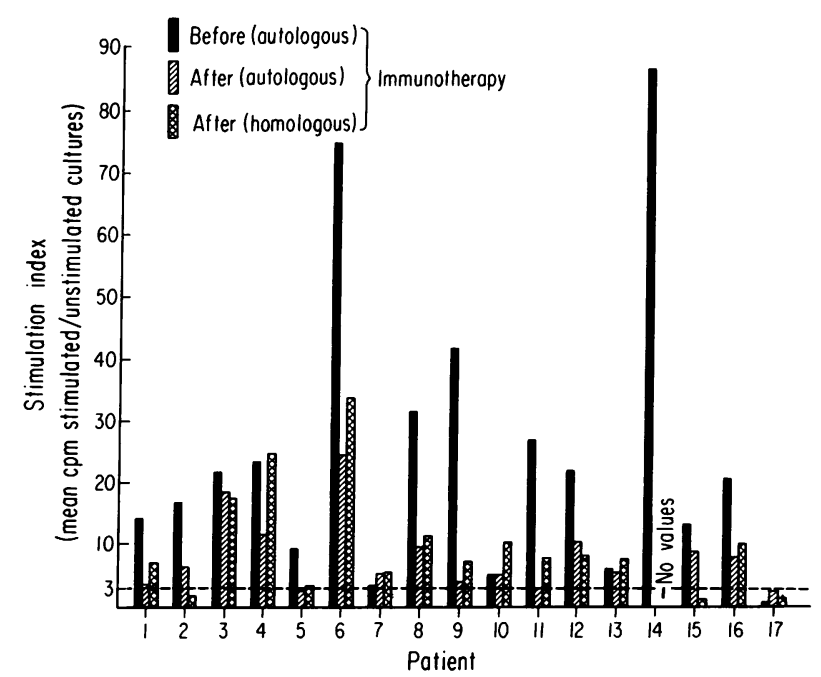

FIgURE 4 Tritiated thymidine uptake shown as stimulation indices of patients before and after immunotherapy. After therapy cultures were also carried out in homologous serum.

patients' cells showed no change in responsiveness to SK-SD antigen after immunotherapy.

$M F$ production. Lymphocytes from patients and controls were evaluated for their ability to elaborate a mitogenic material which nonspecifically activates other lymphocytes to incorporate increased amounts of $\left[{ }^{3} \mathrm{H}\right]$ thymidine (Fig. 5). Ragweed-sensitive patients, in contrast to normal controls, produce greater amounts of $\mathrm{MF}$ in vitro in response to $\mathrm{RAgE}$. The highest cpm values obtained from lymphocytes of normal subjects were 7,000 . Cells from all but one patient in this study produced significant amounts of MF before immunotherapy. The mean pretreatment value was $30,226 \mathrm{cpm}$. Immunotherapy was followed by a decrease in MF production in 11 of the study patients. An increase in MF occurred in four of the patients. The mean posttreatment cpm was 13,050 . A paired $t$ test of the MF produced before and after treatment did not reveal a statistical difference.

MIF production. Supernates from patient and control lymphocytes activated by RAgE and SK-SD were assayed for MIF before and after immunotherapy. The inhibitory activity of active supernates was considered significant when $20 \%$ inhibition of migration of the indicator cells was observed. As seen in Fig. 6, significant MIF activity was found in 12 of the ragweed patients before immunotherapy. This was reduced to $20 \%$ or less in seven patients after immunotherapy. Two patients produced significant amounts of MIF after immunotherapy when they had not done so before. The mean MIF response to $\mathrm{RAgE}$ before immunotherapy was $23.2 \%$ inhibition, which decreased to $14.6 \%$ after treat-

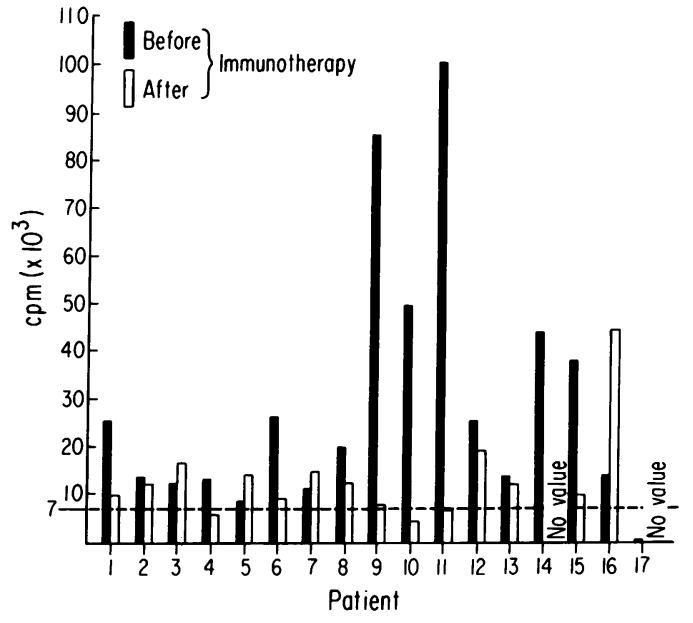

FIGURE 5 MF activity of supernates (diluted $1 / 3$ and 1/6) obtained from patient lymphocytes before and after immunotherapy. The cells were stimulated with $75 \mu \mathrm{g}$ protein $/ \mathrm{ml}$ of $\mathrm{RAgE}$ to generate MF.

ment. This decrease in MIF production was significant $(P<0.05)$. The patients' cells were also cultured with SK-SD and the amounts of MIF with this antigen before and after immunotherapy were similar.

Effect of immunotherapy on symptoms. All but one of the patients reported symptom improvement in the ragweed season following immunotherapy as compared to the pretreatment ragweed season. Three of the patients reported no symptoms in the posttreatment ragweed season. This treatment response is similar to other previous reports using high-dose therapy (17-24).

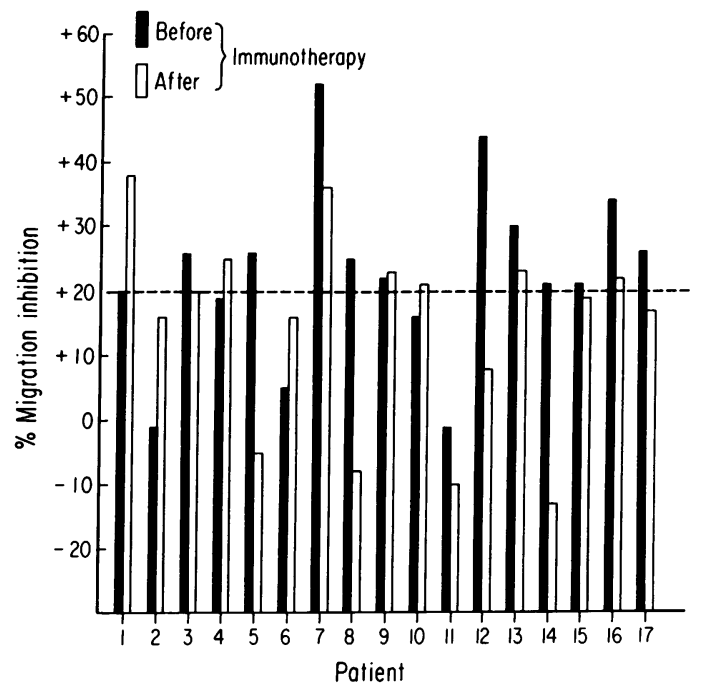

FIGURE 6 Macrophage MIF activity of supernates obtained from patient lymphocytes stimulated by $\mathrm{RAgE}$ before and after immunotherapy. 
Correlation of $P$ in in vitro assays. Data from the in vitro assays, including the degree of change in these assays following immunotherapy, were ranked. A coefficient of correlation was determined among these changes as well as among the degree of symptom improvement reported and with the amount of immunotherapy employed. There was a highly significant correlation between the increase in IgGAR and the degree of symptom improvement $\left(r^{*}=0.76 ; P<0.001\right)$. There was an inverse relationship between the amount of IgGAR and the amount of $\operatorname{IgEAR}\left(r^{*}=0.56 ; P<\right.$ $0.05)$. Furthermore, there was a direct correlation between the increase in IgGAR and the total dose of ragweed extract administered $\left(r^{\circ}=0.50 ; P<0.05\right)$. The decrease in lymphocyte proliferation to $\mathrm{RAgE}$ in homologous plasma after immunotherapy correlated with the increase in IgGAR $\left(r^{*}=0.49 ; P<0.05\right)$. There were no other correlations noted among the in vitro tests. A summary of the effects of immunotherapy on the immunologic parameters measured in this study is shown in Table I.

\section{DISCUSSION}

Specific immunotherapy is a widely accepted approach to the treatment of pollen-induced allergic rhinitis (1725) ; however, the immunologic events responsible for the reported symptomatic improvement are unclear. The purpose of the present study was to examine the possible mechanisms by which immunotherapy might alter immune responsiveness utilizing newly developed in vitro techniques for measuring humoral and cellular hypersensitivity responses. These techniques were employed in a prospective study of ragweed hayfever sufferers before and after specific immunotherapy.

We have confirmed the observations of others that im- munotherapy is associated with a decrease in specific $\operatorname{Ig} \mathrm{E}$ antibodies and an increase in specific IgG blocking antibodies $(17,22)$. Furthermore, we found a reciprocal relationship between the degree of change in these classes of antibody with immunotherapy. That is, those patients developing higher levels of IgGAR had a greater decrease in IgEAR. Higher IgG antibody titers were also found in those patients reporting greater clinical improvement following specific immunotherapy. Clinical improvement could not be correlated with the amount of decrease in IgEAR. These observations have also been made by Lichtenstein et al. (17).

Of interest were a number of patients $(6 / 17)$ who had a clinical diagnosis of ragweed hayfever but who were relatively insensitive to $\mathrm{RAgE}$ in vitro in terms of leukocyte histamine release and having insignificant levels of IgEAR. These patients did develop IgGAR in response to immunotherapy and did report quantitative symptom improvement. None of this group developed $\mathrm{IgE}$ antibody to ragweed or leukocyte sensitivity to $\mathrm{RAgE}$ as a result of immunotherapy, however. This suggests that at least some ragweed patients may have symptoms as a result of sensitivity to antigenic components other than $\mathrm{RAgE}$ in the ragweed preparation. Furthermore, it appears that atopic patients do not develop in vitro evidence of immediate hypersensitivity to $\mathrm{RAgE}$ as the result of prolonged parenteral injection of this allergen.

In this study, an extract of whole ragweed pollen (WRE) was used for immunotherapy whereas the more purified RAgE was used in the in vitro measurements. We feel this is unlikely to have introduced a significant variable in the experimental results, however. King and Norman (26) found RAgE to be the primary antigenic component of WRE. Antisera to RAgE will remove

TABLE I

Ragweed-Sensitive Patients

\begin{tabular}{lccc}
\hline & \multicolumn{2}{c}{ Immunotherapy } & \\
\cline { 2 - 3 } & Before & After & $t$ test \\
\hline IgEAR (mean \% std) & 82.8 & 49.9 & $P<0.025$ \\
IgGAR (mean \% std) & 10 & 45.5 & $P<0.001$ \\
LHR (median $\mu$ RAgE/ml) & $2.2 \times 10^{-4}$ & $<50 \%$ release & \\
LTT (mean S/C) & 20.7 & 8.0 & $P<0.005$ \\
A/A (RAgE) & 20.7 & 9.8 & $P<0.005$ \\
A/H (RAgE) & 17.7 & 15.3 & NS \\
SK-SD & 30,226 & 13,050 & $P<0.10$ \\
MF (mean cpm) & 23.2 & 14.6 & $P<0.05$ \\
MIF (mean \% inhibition) & 32.6 & 30.8 & NS \\
RAgE & & & \\
SK-SD & & & \\
\hline
\end{tabular}

LHR, leukocyte histamine release; LTT, lymphocyte transformation test; A, autologous; $\mathrm{H}$, homologous. 
more than $90 \%$ of the skin test activity of WRE (4). Immunotherapy with WRE gives similar clinical results to those obtained with $\mathrm{RAgE}$ (5). In vitro, $\mathrm{RAgE}$ is preferred to the nonimmunologic stimulation of viable lymphocytes which might occur secondary to nonantigenic components of WRE. Similarly, the assay for serum antibody, IgGAR, requires that the more purified $\mathrm{RAgE}$ be radiolabeled in order to insure specificity. Leukocyte sensitivity to $\mathrm{RAgE}$ for histamine release has been found to parallel leukocyte sensitivity to WRE for histamine release in all but the more insensitive ragweed-sensitive patients (6).

We have also confirmed decreased responsiveness of leukocytes for antigen-induced histamine release following specific immunotherapy (22-24). Of interest is our observation that this reduction in leukocyte sensitivity does not regularly parallel the quantitative decrease in specific IgEAR. This apparent discrepancy might be explained by individual variation in response to immunotherapy, by variation in the affinity of the $\operatorname{IgE}$ antibody for target cells, and by the importance of sensitivity to ragweed antigens other than $\mathrm{RAgE}$ in some of the patients.

While ragweed hayfever is usually associated with IgE-mediated responses, we and others have also found that these patients have lymphocytes which are activated by $\operatorname{RAgE}(2,7,8,27,28)$. Lymphocytes from ragweed hayfever patients incorporate increased amounts of $\left[{ }^{3} \mathrm{H}\right]$ thymidine and produce at least two lymphocyte mediators, $\mathrm{MIF}$ and $\mathrm{MF}$, in response to the $\mathrm{RAgE}$. Specific immunotherapy, as shown in the present study, induces alterations in lymphocyte responsiveness. Both lymphocyte proliferation and mediator production were significantly reduced after immunotherapy. This diminished responsiveness appeared to be specific for $\mathrm{RAgE}$ since lymphocyte reactivity to SK-SD remained the same following immunotherapy. In some nonprospective studies, the effect of immunotherapy on in vitro lymphocyte responses has been variable. Maini et al. found lymphocyte MIF production in grass sensitive patients who had received immunotherapy as compared to a group of patients who had not (3). Massie and Wutanasupta found a similar incidence of MIF production in untreated as compared to treated atopic patients (29). More recently Gatien et al. have reported a decrease in lymphocyte responsiveness associated with immunotherapy (28). The latter investigators used a purified population of thymus-derived lymphocytes ( $\mathrm{T}$ cells) obtained from ragweed-sensitive patients, some of whom were receiving immunotherapy. The $T$ cells in the group of patients on treatment underwent significantly less proliferation when challenged with $\mathrm{RAgE}$.

We have been able to compare the effect of in vitro lymphocyte responsiveness with humoral antibody responses resulting from immunotherapy. Lymphocytes were cultured for $\left[{ }^{3} \mathrm{H}\right]$ thymidine incorporation in both autologous and homologous sera in order to detect the possible influence of antibody in the form of antigenantibody complexes present in the posttreatment sera. In contrast to the report of Romagnani et al. (30) and Anderson et al. (31), we found no indication that antigen-antibody complexes in the sera significantly affected the in vitro lymphocyte proliferative response.

The increase in IgGAR levels was associated with accumulative treatment doses $(P=<0.05)$, whereas the lymphocyte responsiveness did not appear to be dose related. The decrease in lymphocyte proliferation subsequent to immunotherapy did not correlate directly with the decrease in lymphocyte MIF or MF production. On the other hand, there was a direct correlation $\left(r^{*}=0.59 ; P<0.05\right)$ after therapy between the decrease in leukocyte histamine release and the decrease in production of MIF.

A diminished lymphocyte responsiveness to $\mathrm{RAgE}$ after immunotherapy was not dependent upon a pretreatment sensitivity to the antigen as manifest by leukocyte histamine release or IgEAR titers.

Recently, important control mechanisms have been described involving a subpopulation of $T$ cells which modulates bone marrow-derived lymphocyte function (32-36). The regulatory role is bidirectional and includes $\mathrm{T}$ cells, bone marrow-derived lymphocytes, and macrophages $(37,38)$. In the present study, immunotherapy induced a suppression in the levels of specific $\operatorname{IgEAR}$, but stimulated the formation of IgGAR. There are several mechanisms that can be postulated to account for suppression of certain humoral and cellular responses and allow others to be expressed. One mechanism might involve the generation of suppressor $\mathrm{T}$ cells which could inhibit IgE-producing cells $(32,35)$ and possibly other lymphocyte functions such as proliferation and mediator production. Since the $T$ helper cells for $\mathrm{IgE}$ and $\mathrm{IgG}$ antibody production appear to be distinct subpopulations (34), it is possible that the suppressor cell could selectively inhibit the $\operatorname{IgE}$ helper cell but not affect the generation of IgG helper cells. An alternative mechanisms might involve the induction of a state of tolerance by the repeated injection of increasing doses of antigen. In this situation antigen binding might actually be increased and a form of receptor blockage might result (39). It would have been of interest to measure the numbers of IgEAR-binding lymphocytes before and after therapy. We are not able to reconcile a state of tolerance resulting from immunotherapy with $\mathrm{IgE}$ suppression and decreased cellular-immune reactivity on the one hand, and increased IgG production on the other.

T-cell function is probably determined by histocompatability-linked immune response (Ir) genes (40). The response observed in this study to immunotherapy may 
be characteristic of atopic patients, a state which may also be conditioned by certain HL-A genotypes. It is not clear whether atopic patients are "programmed" to produce IgE antibodies when presented with ragweed pollen as such in the environment and IgG antibodies upon parenteral administration of antigen. In any event, immunotherapy is a clinically useful tool which appears to result in widespread changes in specific immunologic reactivity to the antigen being used to desensitize the patient.

\section{ACKNOWLEDGMENTS}

We wish to acknowledge the excellent technical assistance of Ms. Linda Gray. The authors thank Dr. Lawrence Lichtenstein and Ms. Anne Sobotka for their help in setting up the IgGAR assay.

This work was supported by the Clinical Investigation Service, Walter Reed Army Medical Center, Washington, D. C.

\section{REFERENCES}

1. Ishizaka, K., and T. Ishizaka. 1970. Biological function of $\gamma \mathrm{E}$ antibodies and mechanisms of reaginic hypersensitivity. Clin. Exp. Immunol. 6: 25-42.

2. Rocklin, R. E., H. Pence, H. Kaplan, and R. Evans. 1974. Cell-mediated immune response of ragweed-sensitive patients to ragweed antigen $E$. In vitro lymphocyte transformation and elaboration of lymphocyte mediators. J. Clin. Invest. 53: 735-744.

3. Maini, R. N., D. C. Dumonde, J. A. Faux, F. E. Hargreave, and J. Pepys. 1971. The production of lymphocyte mitogenic factor and migration-inhibition factor by antigen-stimulated lymphocytes of subjects with grass pollen allergy. Clin. Exp. Immunol. 9: 449-465.

4. King, T. P., P. S. Norman, and J. T. Connell. 1964 Isolation and characterization of allergens from ragweed pollen, II. Biochemistry. 3: 458-468.

5. Norman, P. S., W. L. Winkenwerder, and L. M. Lichtenstein. 1968. Immunotherapy of hay fever with ragweed antigen $\mathrm{E}$ : comparisons with whole pollen extract and placebos. J. Allergy. 42: 93-108.

6. Norman, P. S., and L. M. Lichtenstein. 1973. Capacity of purified antigens and whole pollen extracts to release histamine from leukocytes of hay fever patients. $J$. $\mathrm{Al}$ lergy Clin. Immunol. 52: 94-104.

7. Girard, J. P., N. R. Rose, M. L. Kunz, S. Kobayashi, and C. E. Arbesman. 1967. In vitro lymphocyte transformation in atopic patients: induced by antigens. $J$. Allergy. 39: 65-81.

8. Richter, M., and C. K. Naspitz. 1968. The in vitro blastogenic response of lymphocytes of ragweed-sensitive individuals. J. Allergy. 41: 140-151.

9. Wide, L., H. Bennich, and S. G. O. Johansson. 1967. Diagnosis of allergy by an in-vitro test for allergen antibodies. Lancet. 2: 1105-1107.

10. Greenwood, F. C., W. M. Hunter, and J. S. Glover. 1963. The preparation of ${ }^{131}$ I-labeled human growth hormone of high specific radioactivity. Biochem. J. 89: 114 123.

11. May, C. D., M. Lyman, R. Alberto, and J. Cheng. 1970. Procedures for immunochemical study of histamine release from leukocytes with small volumes of blood. $J$. Allergy. 46: 12-20.
12. Sobotka, A. K., K. Ishizaka, and L. M. Lichtenstein. 1975. Measuring blocking antibody by an IgG-antigen binding assay. J. Allergy Clin. Immunol. 55: 73. (Abstr.)

13. Thorsby, E., and A. Bratlie. 1970. A rapid method for preparation of pure lymphocyte suspensions. In Histocompatibility Testing. P. I. Terasaki, editor. Munksgaard, A/S, Copenhagen. 655-656.

14. Rocklin, R. E., G. Reardon, A. Sheffer, W. H. Churchill, and J. R. David. 1970. Dissociation between two in vitro correlates of delayed hypersensitivity: absence of migration inhibitory factor (MIF) in the presence of antigen-induced incorporation of ${ }^{3} \mathrm{H}$-thymidine. Proc. Fifth Leucocyte Cult. Conf. 639-648.

15. Rocklin, R. E., O. L. Meyers, and J. R. David. 1970. An in vitro assay for cellular hypersensitivity in man. J. Immunol. 104: 95-102.

16. Snedecor, G. W., and W. G. Cochran. 1967. Statistical Methods. The Iowa State University Press, Ames, Iowa. 6th edition.

17. Lichtenstein, L. M., K. Ishizaka, P. S. Norman, A. K. Sobotka, and B. M. Hill. 1973. IgE antibody measurements in ragweed hay fever. Relationship to clinical severity and the results of immunotherapy. J. Clin. Invest. $52: 472-482$.

18. Baldwin, L. B., and J. Glaser. 1936-1937. Effect of treatment on skin and mucous membrane sensitivity and on reagins in hayfever. J. Allergy. 8: 129-142.

19. Norman, P. S. 1969. A rational approach to desensitization. J. Allergy. 44: 129-145.

20. Lowell, F. C., and W. Franklin. 1965. A double blind study of the effectiveness and specificity of injection therapy in ragweed hay fever. N. Engl. J. Med. 273: 675-679.

21. Levy, D. A., L. M. Lichtenstein, E. O. Goldstein, and K. Ishizaka. 1971. Immunologic and cellular changes accompanying the therapy of pollen allergy. J. Clin. Invest. 50: 360-369.

22. Lichtenstein, L. M., P. S. Norman, W. L. Winkenwerder, and A. G. Osler. 1966. In vitro studies of human ragweed allergy: changes in cellular and humoral activity associated with specific desensitization. J. Clin. Invest. 45: 1126-1136.

23. Lichtenstein, L. M., P. S. Norman, and W. L. Winkenwerder. 1968. Clinical and in vitro studies on the role of immunotherapy in ragweed hay fever. Am. J. Med. 44 : 514-524.

24. Sadan, N., M. B. Rhyne, E. D. Mellits, E. O. Goldstein, D. A. Levy, and L. M. Lichtenstein. 1969. Immunotherapy of pollinosis in children: investigation of the immunologic basis of clinical improvement. N. Engl. J. Med. 280: 623-627.

25. Noon, L. 1911. Prophylactic inoculation against hay fever. Lancet. I : 1572-1573.

26. King, T. P., and P. S. Norman. 1962. Isolation studies of allergens from ragweed pollen. Biochemistry. 1: 709720.

27. Brostoff, J., and I. M. Roitt. 1969. Cell-mediated (delayed) hypersensitivity in patients with summer hayfever. Lancet. 2 : 1269-1272.

28. Gatien, J. G., E. Merler, and H. R. Colten. 1975. Allergy to ragweed antigen $E$ : effect of specific immunotherapy on the reactivity of human $\mathrm{T}$ lymphocytes in vitro. Clin. Immunol. Immunopathol. 4: 32-37.

29. Massie, F. S., and R. Wutanasupta. 1972. Detection of delayed hypersensitivity in ragweed pollinosis by an in vitro method. Ann. Allergy. 30: 676-684. 
30. Romagnani, S., G. Biliotti, and M. Ricci. 1975. Depression of grass pollen-induced lymphocyte transformation by serum from hyposensitized patients. Clin. Exp. Immunol. 19 : 83-91.

31. Anderson, J. A., S. R. Lane, W. A. Howard, S. Leikin and J. J. Oppenheim. 1974. The effect of hyposensitization on alternaria-induced lymphocyte blastogenesis. Cell. Immunol. 10: 442-449.

32. Gershon, R. K. 1974. T cell control of antibody production. Contemp. Top. Immunobiol. 3: 1-40.

33. Allison, A. C., A. M. Denman, and R. D. Barnes. 1971. Cooperating and controlling functions of thymusderived lymphocytes in relation to autoimmunity. Lancet. $2: 135-140$

34. Kishimoto, T., and K. Ishizaka. 1973. Regulation of antibody response in vitro. V. Effect of carrier-specific helper cells on generation of hapten-specific memory cells of different immunoglobulin classes. J. Immunol. $111: 1-9$.

35. Okumura, K., and T. Tada. 1971. Regulation of homo- cytotropic antibody formation in the rat. III. Effect of thymectomy and splenectomy. J. Immunol. 106: 10191025.

36. Mitchell, G. F. 1975. A proposal that one in vivo function of $T$ cells is to regulate the availability of antigen for B cells. Transplant. Rev. 23 : 119-125.

37. Katz, D. H., and B. Benacerraf. 1972. The regulatory influence of activated $\mathrm{T}$ cells on $\mathrm{B}$ cell responses to antigen. Adv. Immunol. 15 : 1-94.

38. Unanue, E. R. 1972. The regulatory role of macrophages in antigenic stimulation. Adv. Immunol. 15: 95165.

39. Katz, D. H., and B. Benacerraf, editors. 1974. Immunological Tolerance: Mechanisms and Potential Therapeutic Applications. Academic Press, Inc., New York. 645 pp.

40. Katz, D. H., and B. Benacerraf. 1975. The function and interrelationships of $\mathrm{T}$-cell receptors, Ir genes and other histocompatibility gene products. Transplant. Rev. 22 : $175-195$. 